\title{
Сорбционная очистка растворов щелочных металлов от примесей щелочноземельных и цветных металлов
}

\author{
Милютин В.В. ${ }^{1}$, Некрасова Н.А. ${ }^{1}$, Рудских В.В. ${ }^{2}$, Волкова Т.С. ${ }^{2}$ \\ ${ }^{I}$ ФГБУН Институт физической химии и электрохимии имени А.Н. Фрумкина РАН \\ (ИФХЭ РАН), Москва \\ ${ }^{2}$ Федеральное государственное унитарное предприятие «Производственное объединение «Маяк» \\ (ФГУП «ПО «Маяк»), Озерск
}

Поступила в редакцию 23.02.2018 г.

DOI: https://doi.org/10.17308/sorpchrom.2018.18/540

В статье приводятся результаты исследований по сорбционному извлечению примесей кальция, магния, никеля, меди, кобальта и цинка из растворов солей щелочных металлов - $\mathrm{NaHCO}_{3}, \mathrm{LiH}-$ $\mathrm{CO}_{3}$ и $\mathrm{LiCl}$ с использованием сульфокатионитов, фосфорнокислых и карбоксильных катионитов, а также хелатных иминокарбоксильных ионитов. В статических условиях определены значения статической обменной емкости исследованных сорбентов по примесным ионам. В динамических условиях определены значения емкости до проскока и полной динамической емкости. Показано, что для глубокой очистки солей щелочных металлов от щелочноземельных и цветных металлов наиболее эффективными являются иминокарбоксильные сорбенты Amberlite IRC 748, Purolite S930, а также их российский аналог - сорбент AXIONIT 3S производства AO «Аксион РДМ».

Ключевые слова: сорбция, иониты, соли щелочных металлов, литий, очистка.

\section{Sorption purification of solutions of alkali metals from impurities of alkaline-earth and non-ferrous metals}

\author{
Milyutin V.V. ${ }^{1}$, Nekrasova N.A. ${ }^{1}$, Rudskikh V.V. ${ }^{2}$, Volkova T.S. ${ }^{2}$ \\ ${ }^{I}$ Federal State Budget Science Institution Frumkin Institute of Physical Chemistry and Electrochemistry of \\ the Russian Academy of Sciences (IPCE RAS), Moscow \\ ${ }^{2}$ Federal State Unitary Enterprise PA Mayak, (FSUE PA Mayak), Ozyersk
}

The article is devoted to the study of the sorption of magnesium, calcium, nickel, copper, cobalt and zinc ions from solutions of alkali metal salts - $\mathrm{NaHCO}_{3}, \mathrm{LiHCO}_{3}$ and $\mathrm{LiCl}$, using various ion exchangers: sulphocationite, phosphoric acid and carboxyl cation exchangers, and chelated iminocarboxyl ion exchangers. The results of the experiments in batch conditions showed that the sulfocathionite TOKEM 308 (analogue KU-2 $\times 8$, Russia) almost does not sorb the non-ferrous metals and magnesium from the $\mathrm{NaHCO}_{3}$ solution. All the other sorbents has a high sorption capacity with respect to $\mathrm{Ni}, \mathrm{Ca}, \mathrm{Mg}$, and Co ions. The sorption of copper is the worst, due to the formation of strong carbonate copper complexes. Iminocarboxylic chelate sorbents - Amberlite IRC 748 («Rohm and Haas», USA), Purolite S930 (Purolite, UK) and AXIONIT 3S (JSC Axion RDM, Russia) has the maximum values of the batch exchange capacity with respect to $\mathrm{Ca}, \mathrm{Ni}$, $\mathrm{Cu}$, and $\mathrm{Zn}$ ions in $\mathrm{LiHCO}_{3}$ solution. For the sorption purification of $\mathrm{LiCl}$ solution (pH 1.4) from impurities of calcium, magnesium, copper and nickel ions, iminocarboxyl ionites are also the most acceptable, however in this case the capacity of all the sorbents is several times lower than in the case of weak alkaline solutions of $\mathrm{NaHCO}_{3}$ and $\mathrm{LiHCO}_{3}$.

Results of flow rate experiments on the purification of $\mathrm{NaHCO}_{3}$ and $\mathrm{LiHCO}_{3}$ solutions from the impurities of magnesium, calcium, nickel, copper, as a whole, confirmed the data of batch experiments on the maximum efficiency of iminocarboxyl ion exchangers. 
The experiences has demonstrated that the iminocarboxyl chelate ionites are highly promising sorbents for deep purification of alkali metal salts from impurities of alkaline earth and non-ferrous metals.

Keywords: sorption, ion exchangers, alkali metal salts, lithium, purification.

\section{Введение}

В настоящее время соединения редких щелочных металлов, в частности лития, находят широкое применение в различных отраслях науки и техники: при изготовлении химических источников тока, для получения специальных сплавов, в ядерной энергетике и промышленности и др. Практически во всех сферах применения основным требованием к литию и его соединениям является его высокая химическая чистота. До последнего времени для получения лития и его очистки от примесей широко использовался электрохимический метод с ртутным катодом [1]. Очевидно, что данная технология не отвечает современным требованиям экологической безопасности и должна быть заменена на более безопасную.

Для выделения лития из растворов могут быть использованы различные методы, основанные на сорбционных и экстракционных процессах. Для сорбционного извлечения лития из растворов используются, как органические ионообменные смолы $[2,3]$, так и неорганические сорбенты на основе оксигидратов титана, марганца или алюминия [4-9]. Вопросы очистки солей лития от примесей посторонних металлов методом ионного обмена изучены недостаточно полно.

В связи с этим, целью настоящей работы являлось изучение возможности сорбционной очистки солей щелочных металлов, в первую очередь, лития от примесей щелочноземельных и цветных металлов.

\section{Теоретическая часть}

При получении высокочистых соединений щелочных металлов основными примесями, определяющие чистоту готовых продуктов являются щелочноземельные металлы, магний, а также продукты коррозии технологической аппаратуры - ионы цветных металлов и железа. Для удаления вышеперечисленных примесей из растворов солей щелочных металлов перспективным является сорбционный метод с использованием ионитов, обладающих селективностью к двух- и многозарядным ионам в присутствии избытка однозарядных ионов щелочных металлов. Для этой цели могут быть использованы сильнокислотные сульфокатиониты, среднекислотные фосфорнокислые катиониты, слабокислотные карбоксильные катиониты, а также хелатные иминокарбоксильные катиониты. Ряды селективности указанных ионитов приведены ниже [10]:

сульфокатиониты: $\mathrm{Fe}^{3+}>\mathrm{Ba}^{2+}>\mathrm{Sr}^{2+}>\mathrm{Ca}^{2+}>\mathrm{Ni}^{2+}>\mathrm{Cu}^{2+}>\mathrm{Co}^{2+}>\mathrm{Zn}^{2+}>\mathrm{Mg}^{2+}>$ $\mathrm{K}^{+}>\mathrm{Na}^{+}>\mathrm{H}^{+}>\mathrm{Li}^{+}$

фосфорнокислые катиониты: $\mathrm{Fe}^{3+}>\mathrm{H}^{+}>\mathrm{Cu}^{2+}>\mathrm{Zn}^{2+}>\mathrm{Co}^{2+}>\mathrm{Ni}^{2+}>\mathrm{Ca}^{2+}>\mathrm{Sr}^{2+}$ $>\mathrm{Ba}^{2+}>\mathrm{Li}^{+}>\mathrm{Na}^{+}>\mathrm{K}^{+}$

карбоксильные катиониты: $\mathrm{H}^{+}>>\mathrm{Fe}^{3+}>\mathrm{Ba}^{2+}>\mathrm{Sr}^{2+}>\mathrm{Ca}^{2+}>\mathrm{Mg}^{2+}>\mathrm{K}^{+}>\mathrm{Na}^{+}>\mathrm{Li}^{+}$. иминокарбоксильные катиониты: $\mathrm{Cu}^{2+}>>\mathrm{Fe}^{3+}>\mathrm{Ni}^{2+}>\mathrm{Zn}^{2+}>\mathrm{Co}^{2+}>>\mathrm{Ba}^{2+}>\mathrm{Ca}^{2+}$ $>\mathrm{Mg}^{2+}>>\mathrm{Li}^{+}>\mathrm{Na}^{+}>\mathrm{K}^{+}$.

Как видно из приведенных рядов селективности вышеперечисленные типы сорбентов могут быть использованы для очистки солей щелочных металлов от примесей щелочноземельных и цветных металлов. 


\section{Эксперимент}

В экспериментах по очистке растворов солей щелочных металлов использовали сорбенты, характеристики которых приведены в табл. 1.

Таблица 1. Характеристика исследованных сорбентов

\begin{tabular}{|c|c|c|c|}
\hline Марка сорбента & Тип сорбента & $\begin{array}{c}\text { Функциональные } \\
\text { группы }\end{array}$ & Производитель \\
\hline TOKЕМ 308 & $\begin{array}{c}\text { сильнокислотный } \\
\text { сульфокатионит }\end{array}$ & $-\mathrm{SO}_{3} \mathrm{H}$ & $\begin{array}{c}\text { НПО «ТОКЕМ», } \\
\text { Россия, г. Кемерово }\end{array}$ \\
\hline ТОКЕМ КФП & $\begin{array}{l}\text { среднекислотный фос- } \\
\text { форнокислый катионит }\end{array}$ & $\begin{array}{c}-\mathrm{PO}(\mathrm{OH})_{2} \text { или } \\
-\mathrm{OPO}(\mathrm{OH})_{2}\end{array}$ & $\begin{array}{c}\text { НПО «ТОКЕМ», } \\
\text { Россия, г. Кемерово }\end{array}$ \\
\hline TOКЕМ 200 & $\begin{array}{l}\text { слабокислотный кар- } \\
\text { боксильный катионит }\end{array}$ & $-\mathrm{COOH}$ & $\begin{array}{c}\text { НПО «ТОКЕМ», } \\
\text { Россия, г. Кемерово }\end{array}$ \\
\hline Purolite S957 & $\begin{array}{c}\text { сульфофосфоновый } \\
\text { катионит }\end{array}$ & -Ph- $\left(\mathrm{SO}_{3} \mathrm{H}\right) \mathrm{PO}_{3} \mathrm{H}_{2}$ & $\begin{array}{c}\text { «Purolite», Велико- } \\
\text { британия }\end{array}$ \\
\hline Purolite S930 & $\begin{array}{c}\text { иминокарбоксильный } \\
\text { катионит }\end{array}$ & $-\mathrm{N}\left(\mathrm{CH}_{2} \mathrm{COOH}\right)_{2}$ & $\begin{array}{c}\text { «Purolite», Велико- } \\
\text { британия }\end{array}$ \\
\hline Amberlite IRC 748 & $\begin{array}{c}\text { иминокарбоксильный } \\
\text { катионит }\end{array}$ & $-\mathrm{N}\left(\mathrm{CH}_{2} \mathrm{COOH}\right)_{2}$ & $\begin{array}{c}\text { «Rohm and Haas», } \\
\text { США }\end{array}$ \\
\hline AXIONIT 3S & $\begin{array}{c}\text { иминокарбоксильный } \\
\text { катионит }\end{array}$ & $-\mathrm{N}\left(\mathrm{CH}_{2} \mathrm{COOH}\right)_{2}$ & $\begin{array}{c}\text { АО «Аксион РДМ», } \\
\text { Россия, г. Пермь }\end{array}$ \\
\hline
\end{tabular}

Сорбенты перед началом испытаний обрабатывали в статических условиях раствором азотной кислоты с концентрацией 3 моль/дм ${ }^{3}$ в течение 24 ч, затем промывали дистиллированной водой и высушивали при температуре $60^{\circ} \mathrm{C}$ до постоянного веса.

Сорбционное поведение примесей щелочноземельных и цветных металлов изучали в растворах 1.2 моль/дм ${ }^{3} \mathrm{NaHCO}_{3}, \mathrm{pH}=8.2 ; 1.2$ моль/дм ${ }^{3} \mathrm{LiHCO}_{3}, \mathrm{pH}=8.2$ и 1.2 моль/дм ${ }^{3} \mathrm{LiCl}, \mathrm{pH}=1.4$. Исходные растворы для сорбции готовили следующим образом: в растворы $\mathrm{NaHCO}_{3}, \mathrm{LiHCO}_{3}$ или $\mathrm{LiCl}$ вносили растворы $\mathrm{CaCl}_{2}, \mathrm{MgCl}_{2}$, $\mathrm{CuCl}_{2}, \mathrm{NiCl}_{2}, \mathrm{CoCl}_{2}$ или $\mathrm{ZnCl}_{2}$ до достижения концентрации по металлу примерно 0.1 г/дм³ ${ }^{3}$. Затем растворы перемешивали, выдерживали в течение 24 ч и фильтровали через бумажный фильтр «синяя лента».

Эксперименты по извлечению примесей металлов проводили в статических и динамических условиях по следующим методикам. При проведении статических экспериментов навеску воздушно-сухого сорбента встряхивали с фиксированным объемом модельного раствора при соотношении Т: Ж=1:200 в течение 48 ч. Затем жидкую фазу отфильтровывали через бумажный фильтр «синяя лента» и в фильтрате определяли концентрацию сорбируемого компонента. По полученным результатам анализа рассчитывали значение статической обменной емкости (COE) по формуле:

$$
\text { COE }=\frac{\left(C_{0}-C_{p}\right) \cdot V_{p}}{m_{c}}
$$

где $C_{0}, C_{p}$ - исходная и равновесная концентрация ионов металлов в растворе, ммоль $/ \mathrm{cm}^{3} ; V_{p}$ - объем жидкой фазы, см $^{3} ; m_{c}$ - масса сорбента, г

Динамические эксперименты проводили путем пропускания модельного раствора через слой набухшего сорбента, помещенного в стеклянную колонку. Объем сорбента в колонке - $5.0 \mathrm{~cm}^{3}$, высота слоя сорбента - $7.5 \mathrm{~cm}$, скорость пропускания раствора через колонку $-15 \mathrm{~cm}^{3} /$ ч $(3$ к.о./ч). Подачу растворов проводили при помощи перистальтического насоса «Longerpump» (КНР). Фильтрат после колонки фрак-

Милютин и др. / Сорбционные и хроматографические процессы. 2018. Т. 18. № 3 
ционировали при помощи коллектора фракций и анализировали на содержание сорбируемого компонента. По результатам анализов рассчитывали значения емкости до проскока и полную динамическую емкость.

Концентрации ионов $\mathrm{Ca}, \mathrm{Mg}, \mathrm{Cu}, \mathrm{Ni}$ и $\mathrm{Zn}$ в растворах определяли объемным комплексонометрическим методом [11]. Концентрацию Со определяли радиометрическим методом по гамма-линии радионуклида ${ }^{60}$ Со с использованием спектрометрического комплекса СКС-50М («Грин стар технолоджиз», Москва).

\section{Обсуждение результатов}

Результаты сорбционной очистки раствора $\mathrm{NaHCO}_{3}$ от примесей $\mathrm{Cu}, \mathrm{Ni}, \mathrm{Ca}$, $\mathrm{Mg}$ и Со в статических условиях приведены в табл. 2.

Таблица 2. Значения статической обменной емкости (СОЕ) исследованных сорбентов по $\mathrm{Ca}, \mathrm{Mg}, \mathrm{Cu}, \mathrm{Ni}$ и Со при сорбции из раствора 1.2 моль/дм ${ }^{3} \mathrm{NaHCO}_{3}, \mathrm{pH}=8.2$

\begin{tabular}{|c|c|c|c|c|c|}
\hline \multirow{2}{*}{ Марка сорбента } & \multicolumn{5}{|c|}{ Значение СОЕ, ммоль/ } \\
\cline { 2 - 6 } & $\mathrm{Ca}$ & $\mathrm{Mg}$ & $\mathrm{Cu}$ & $\mathrm{Co}$ & $\mathrm{Ni}$ \\
\hline TOКЕМ 308 & 0.22 & 0.01 & 0.01 & 0.01 & 0.01 \\
\hline TOКЕМ КФП & 0.24 & 0.73 & 0.09 & 0.61 & 0.46 \\
\hline TOKЕM 200 & 0.35 & 1.05 & 0.10 & 0.66 & 0.62 \\
\hline Purolite S957 & 0.30 & 0.92 & 0.05 & 0.63 & 0.52 \\
\hline Amberlite IRC 748 & 0.33 & 0.80 & 0.59 & 0.67 & 0.93 \\
\hline
\end{tabular}

Приведенные результаты показывают, что сульфокатионит ТОКЕМ 308 (аналог КУ-2×8) практически не сорбирует цветные металлы и магний на фоне макроколичеств $\mathrm{Na}$. Все остальные изученные сорбенты проявляют высокую сорбционную активность по отношению к $\mathrm{Ni}, \mathrm{Ca}, \mathrm{Mg}$ и Со. Хуже всего протекает сорбция меди, что связано, по-видимому, с образованием прочных карбонатных комплексов меди. Наилучшими сорбционными характеристиками по отношению к меди в растворе $\mathrm{NaHCO}_{3}$ обладают иминокарбоксильный катионит Amberlite IRC 748.

Для определения сорбционных характеристик в динамических условиях были выбраны сорбенты TOКЕМ 200 и Amberlite IRC 748. Результаты динамических экспериментов по сорбции суммы $\mathrm{Ca}+\mathrm{Mg}, \mathrm{Cu}$ и $\mathrm{Ni}$ из раствора $\mathrm{NaHCO}_{3}$ на данных сорбентах приведены на рис. 1-3 и в табл. 3.

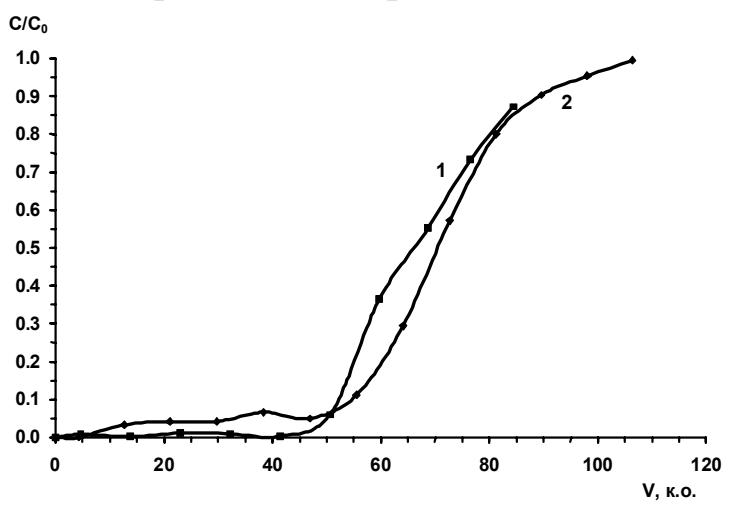

Рис. 1. Выходные кривые сорбции суммы $\mathrm{Ca}+\mathrm{Mg}$ из раствора $\mathrm{NaHCO}_{3}$ на сорбентах ТОКЕМ 200 (1)

и Amberlite IRC 748

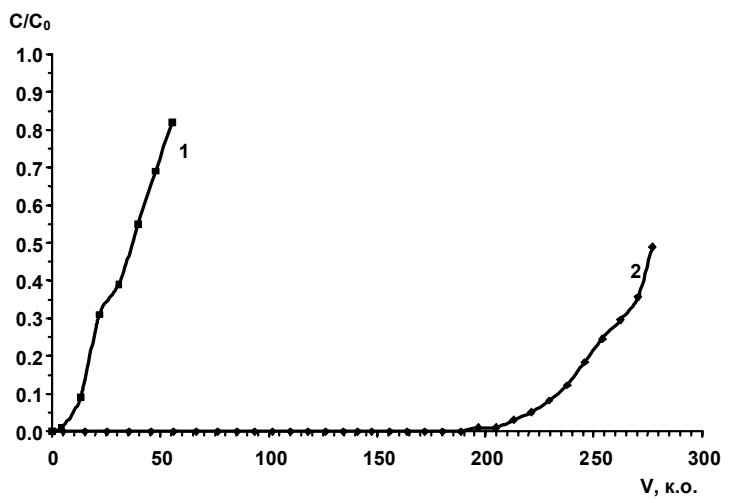

Рис. 2. Выходные кривые сорбции $\mathrm{Cu}$ из раствора $\mathrm{NaHCO}_{3}$ на сорбентах TOKEM 200 (1) и Amberlite IRC 748 (2) 


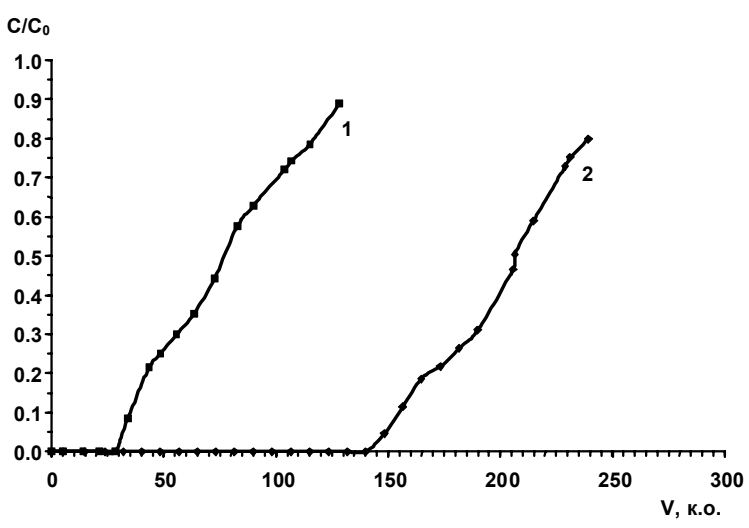

Рис. 3. Выходные кривые сорбции $\mathrm{Ni}$ из раствора $\mathrm{NaHCO}_{3}$ на сорбентах TOКЕМ 200 (1) и Amberlite IRC 748 (2)

Таблица 3. Результаты сорбции $\mathrm{Ca}+\mathrm{Mg}, \mathrm{Cu}$ и $\mathrm{Ni}$ из раствора $\mathrm{NaHCO}_{3}$ в динамических условиях на сорбентах ТОКЕМ 200 и Amberlite IRC 748

\begin{tabular}{|c|c|c|c|c|}
\hline $\begin{array}{c}\text { Сорбируемый } \\
\text { компонент }\end{array}$ & $\begin{array}{c}\text { Марка } \\
\text { сорбента }\end{array}$ & $\begin{array}{c}\text { Объем раствора, } \\
\text { пропущенного до } \\
10 \% \text {-го проскока, } \\
\text { к.о. }\end{array}$ & $\begin{array}{c}\text { Емкость сорбента } \\
\text { до 10\%-го про- } \\
\text { скока, мг/см }\end{array}$ & $\begin{array}{c}\text { Полная дина- } \\
\text { мическая ем- } \\
\text { кость, мг/см }\end{array}$ \\
\hline \multirow{2}{*}{$\mathrm{Ca}+\mathrm{Mg}$} & TOKEM 200 & 52 & 9.6 & 16.0 \\
\cline { 2 - 5 } & $\begin{array}{c}\text { Amberlite IRC } \\
748\end{array}$ & 54 & 9.6 & 12.8 \\
\hline \multirow{2}{*}{$\mathrm{Cu}$} & TOKEM 200 & 13 & 1.7 & 3.7 \\
\cline { 2 - 5 } & $\begin{array}{c}\text { Amberlite IRC } \\
748\end{array}$ & 233 & 23.5 & 27.6 \\
\hline \multirow{2}{*}{$\mathrm{Ni}$} & TOKEM 200 & 34 & 5.1 & 10.9 \\
\cline { 2 - 5 } & $\begin{array}{c}\text { Amberlite IRC } \\
748\end{array}$ & 151 & 19.9 & 26.7 \\
\hline
\end{tabular}

Приведенные результаты показывают, что сорбционные характеристики сорбентов TOКЕМ 200 и Amberlite IRC 748 при очистке раствора гидрокарбоната натрия от суммы $\mathrm{Ca}+\mathrm{Mg}$ примерно одинаковы, а в случае ионов $\mathrm{Cu}$ и $\mathrm{Ni}$ показатели copбента Amberlite IRC 748 в несколько раз выше.

Для проверки возможности очистки раствора $\mathrm{LiHCO}_{3}$ от примесей щелочноземельных $(\mathrm{Ca})$ и цветных металлов $(\mathrm{Cu}, \mathrm{Ni}$ и $\mathrm{Zn})$ были выбраны катиониты ТОКЕМ 200, ТОКЕМ 308, а также иминокарбоксильные хелатные сорбенты различных производителей - Amberlite IRC 748, Purolite S930 и AXIONIT 3S.

Результаты сорбционной очистки раствора $\mathrm{LiHCO}_{3}$ от примесей кальция, меди, никеля и цинка в статических условиях приведены в табл. 4.

Таблица 4. Значения статической обменной емкости (СОЕ) исследованных сорбентов по $\mathrm{Ca}, \mathrm{Cu}, \mathrm{Ni}$ и $\mathrm{Zn}$ при сорбции из раствора 1.2 моль/дм ${ }^{3} \mathrm{LiHCO}_{3}(\mathrm{pH}=8.2)$

\begin{tabular}{|c|c|c|c|c|}
\hline \multirow{2}{*}{ Марка сорбента } & \multicolumn{4}{|c|}{ Значение СОЕ, ммоль/г } \\
\cline { 2 - 5 } & $\mathrm{Cu}$ & $\mathrm{Ni}$ & $\mathrm{Ca}$ & $\mathrm{Zn}$ \\
\hline TOKEM 200 & $<0.01$ & 0.69 & 0.79 & 0.10 \\
\hline TOKEM 308 & 0.29 & $<0.01$ & 0.67 & 0.08 \\
\hline Purolite S930 & 0.72 & 0.82 & 0.65 & 0.12 \\
\hline Amberlite IRC 748 & 0.78 & 0.88 & 0.78 & 0.19 \\
\hline AXIONIT 3S & 0.70 & 0.95 & 0.75 & 0.16 \\
\hline
\end{tabular}


Приведенные данные показывают, что максимальными сорбционными характеристиками по отношению к ионам меди, никеля и кальция в растворе $\mathrm{LiHCO}_{3}$ обладают иминокарбоксильные хелатные сорбенты.

Результаты динамических экспериментов по очистке раствора $\mathrm{LiHCO}_{3}$ от меди на сорбентах Amberlite IRC 748 и Purolite S930 приведены на рис. 4 и в табл. 5.

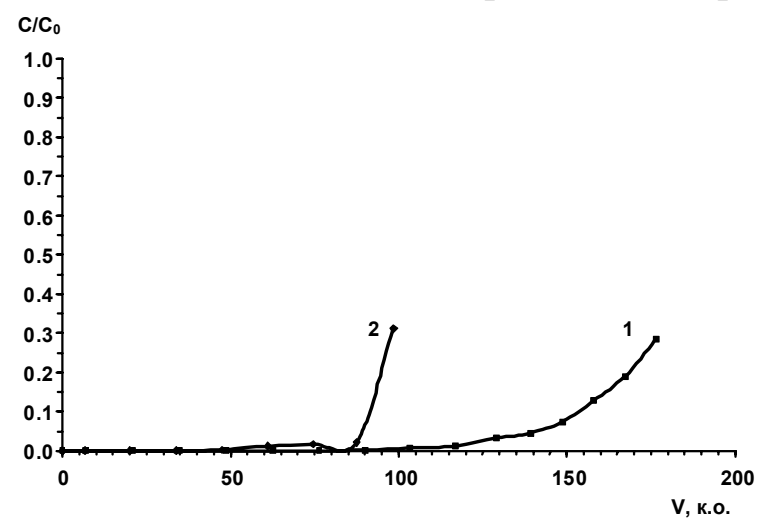

Рис. 4. Выходные кривые сорбции $\mathrm{Cu}$ из раствора $\mathrm{LiHCO}_{3}$ на сорбентах Amberlite IRC 748 (1) и Purolite S930 (2)

Таблица 5. Результаты сорбции ионов $\mathrm{Cu}$ из раствора $\mathrm{LiHCO}_{3}$ в динамических условиях на сорбентах Amberlite IRC 748 и Purolite S930

\begin{tabular}{|c|c|c|c|}
\hline $\begin{array}{l}\text { Марка } \\
\text { сорбента }\end{array}$ & $\begin{array}{c}\text { Объем раствора, пропущен- } \\
\text { ного до 10\%-го проскока, } \\
\text { к.о. }\end{array}$ & 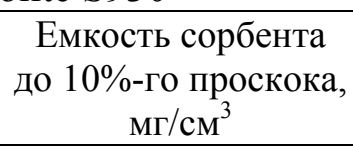 & $\begin{array}{c}\text { Полная динамическая } \\
\text { емкость, мг } / \mathrm{cm}^{3}\end{array}$ \\
\hline $\begin{array}{l}\text { Amberlite } \\
\text { IRC } 748\end{array}$ & (2) & 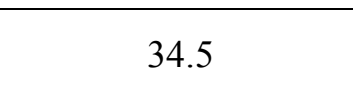 & 48.6 \\
\hline Purolite S930 & 91 & 21.1 & 25.1 \\
\hline
\end{tabular}

Приведенные результаты показывают, что в динамических условиях сорбционные характеристики сорбента Amberlite IRC 748 при очистке раствора гидрокарбоната лития от $\mathrm{Cu}$ несколько выше, по сравнению с сорбентом Purolite S930.

Результаты сорбционной очистки раствора $\mathrm{LiCl}(\mathrm{pH}=1.4)$ от примесей ионов кальция, магния, меди и никеля в статических условиях приведены в табл. 6.

Таблица 6. Значения статической обменной емкости (COE) исследованных сорбентов в $\mathrm{H}$-форме по $\mathrm{Ca}, \mathrm{Mg}, \mathrm{Cu}$ и $\mathrm{Ni}$ при сорбции из раствора 1.2 моль/дм ${ }^{3} \mathrm{LiCl}$ $(\mathrm{pH}=1.4)$

\begin{tabular}{|c|c|c|c|c|}
\hline \multirow{2}{*}{ Марка сорбента } & \multicolumn{4}{|c|}{ Значение СОЕ, ммоль/Г } \\
\cline { 2 - 5 } & $\mathrm{Ca}$ & $\mathrm{Mg}$ & $\mathrm{Cu}$ & $\mathrm{Ni}$ \\
\hline TOKEM 200 & 0.11 & 0.16 & 0.06 & 0.06 \\
\hline TOKEM 308 & $<0.01$ & 0.19 & 0.09 & 0.10 \\
\hline Purolite S930 & 0.05 & 0.11 & 0.25 & 0.05 \\
\hline Purolite S957 & 0.08 & 0.17 & 0.07 & 0.07 \\
\hline Amberlite IRC 748 & 0.11 & 0.16 & 0.26 & 0.07 \\
\hline
\end{tabular}

Приведенные данные показывают, что наилучшими сорбционными характеристиками по отношению к ионам меди, никеля и кальция в растворе $\mathrm{LiCl} \mathrm{c} \mathrm{pH}=1.4$ обладают иминокарбоксильные хелатные сорбенты Purolite S930 и Amberlite IRC748. В целом, емкость иминокарбоксильных хелатных сорбентов по отношению к примесям щелочноземельных $(\mathrm{Ca})$ и цветных металлов в кислых растворах $\mathrm{LiCl}$ в несколь- 
ко раз ниже, по сравнению с емкостью, реализуемой в слабощелочных растворах $\mathrm{NaHCO}_{3}$ и $\mathrm{LiHCO}_{3}$.

\section{Заключение}

Таким образом, для глубокой комплексной очистки растворов солей щелочных металлов $\left(\mathrm{NaHCO}_{3}, \mathrm{LiHCO}_{3}, \mathrm{LiCl}\right)$ от примесей щелочноземельных и цветных металлов наиболее эффективными являются иминокарбоксильные сорбенты Amberlite IRC 748 («Rohm and Haas») и Purolite S930 («Purolite»), а также их российский аналог - сорбент AXIONIT 3S производства AO «Аксион РДМ». Для очистки солей щелочных металлов от примесей щелочноземельных металлов и магния, наряду с иминокарбоксильными сорбентами, могут быть использованы сульфо- и карбоксильные катиониты.

\section{Список литературы}

1. Химия и технология редких и рассеянных элементов. Ч.І. Под ред. К.А. Большакова. М. Высш. Школа. 1976. 368 с.

2. Уланова О.В. Дисс. канд. техн. наук. Иркутск. 2001. 202 с.

3. Клименкова С.Б. Дисс. канд. техн. наук. Иркутск. 2004. 168 с.

4. Бортун А.М., Хайнаков С.А. // Укр. хим. журн. 1990. Т. 56. № 1. С. 1160-1163.

5. Ходяшев Н.Б., Вольхин В.В., Онорин С. А., Сулин Д.В. А.с. 1012486 СССР. 1981.

6. Зильберман М.В., Ченцова Т.В., Чиркова Л.Г. и др. А.с. 1309382 СССР. 1985.

7. Вольхин В.В., Леонтьев Г.В., Онорин С А. Ионноситовые катиониты для селектив-

\section{References}

1. Chemistry and technology of rare and scattered elements, Ch.I. Ed. K.A. Bolshakova, M., High. School, 1976, 368 p. (in Russian)

2. Ulanova O.V., $\mathrm{PhD}$ thesis (technical sciences), Irkutsk, 2001, 202 p. (in Russian)

3. Klimenkova S.B., PhD thesis (technical sciences), Irkutsk, 2004, 168 p. (in Russian)

4. Bortun A.M., Haynakov C.A., Ukranian chem. Journal, 1990, Vol. 56, No 1, pp. 11601163 (in Russian).

5. Khodyashev N.B., Volkhin V.V., Onorin S.A., Sulin D.V., Inventor's certificate No 1012486 (USSR), 1981 (in Russian).

6. Zilberman M.V., Chentsova T.V., Chirkova L.G. et al., Inventor's certificate No 1309382 (USSR), 1985 (in Russian). ной сорбции лития. В кн.: Химия и технология неорганических сорбентов. Пермь. Политехнический институт. 1980. С. 67-71.

8. Саенко Е.В. Дисс. канд. хим. наук. Пермь. 2007. 187 с.

9. Коцупало Н.П., Рябцев А.Д. Химия и технология получения соединений лития из литиеносного гидроминерального сырья. Новосибирск. Гео. 2008. 291 с.

10. Лурье А.А. Хроматографические материалы. М. Химия. 1978. С. 90-91.

11. Шварценбах Г., Флашка Г. Комплексонометрическое титрование. М. Химия. 1970.360 с.

7. Volkhin V.V., Leontieva G.V., Onorin S. A. Ion-carrying cation exchangers for selective sorption of lithium. In: Chemistry and Technology of Inorganic Sorbents. Perm. Polytechnic Institute. 1980, pp. 67-71 (in Russian).

8. Sayenko E.V., $\mathrm{PhD}$ thesis (chemistry sciences), Perm, 2007, 187 p. (in Russian)

9. Kotsupalo N.P., Ryabtsev A.D., Chemistry and technology of obtaining lithium compounds from lithium hydromineral raw materials, Novosibirsk, Geo, 2008, 291 p. (in Russian).

10. Lurie A.A., Chromatographic materials, M., Chemistry, 1978, pp. 90-91 (in Russian).

11. Schwarzenbach G., Flaska G., Complexometric titration, M., Chemistry, 1970, 360 p. (in Russian) 
Милютин Виталий Витальевич - заведующий лабораторией, д.х.н., Федеральное государственное бюджетное учреждение науки Институт физической химии и электрохимии им. А.Н. Фрумкина РАН (ИФХЭ РАН), Москва, тел. 8(495)335-9288

Некрасова Наталья Анатольевна - научный сотрудник, к.х.н., Федеральное государственное бюджетное учреждение науки Институт физической химии и электрохимии им. А.Н. Фрумкина РАН (ИФХЭ РАН), Москва, тел. 8(495)335-9288

Рудских Вячеслав Васильевич - руководитель группы, Федеральное государственное унитарное предприятие «Производственное объединение «Маяк» (ФГУП «ПО «Маяк»), Озерск, тел. (35130)33959

Волкова Татьяна Сергеевна - инженер, к.Х.н., Федеральное государственное унитарное предприятие «Производственное объединение «Маяк» (ФГУП «ПО «Маяк»), Озерск
Milyutin Vitaliy V. - Head of Laboratory, Doctor of Chemical Sciences, Federal State Budget Science Institution Frumkin Institute of Physical Chemistry and Electrochemistry of the Russian Academy of Sciences (IPCE RAS), Moscow, email: vmilyutin@mail.ru

Nekrasova Natalya .A. - Scientist, Ph.D. in Chemistry, Federal State Budget Institution of Science Frumkin Institute of Physical Chemistry and Electrochemistry of the Russian Academy of Sciences (IPCE RAS), Moscow, E-mail: nnekrassova@gmail.com

Rudskikh Vyacheslav V. - Head of group, Federal State Unitary Enterprise PA Mayak, (FSUE PA Mayak), Ozyoksk, e-mail: cpl@po-mayak.ru

Volkova Tatyana S. - engineer, Candidate of Chemical Sciences, Federal State Unitary Enterprise PA Mayak, (FSUE PA Mayak), Ozyoksk, email: cpl@po-mayak.ru. 